
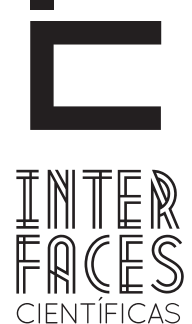

EDUCAÇÃO

\title{
TECNOLOGIAS MÓVEIS E O CENÁRIO EDUCACIONAL BRASLEEIRO: UM ESTUDO DE CASO DA ESCOLA DE ENSINO FUNDAMENTAL MARIA THÉTIS NUNES
}

Lívia Lima Lessa

\section{RESUMO}

Este artigo tem como objetivo realizar reflexões sobre as novas práticas pedagógicas que utilizam as Tecnologias da Informação e Comunicação (TIC) em uma escola de Ensino Fundamental na Zona Norte de Aracaju/SE. Realizou-se um estudo de caso para o desenvolvimento da pesquisa e as análises levam em consideração a direta relação existente entre comunicação e educação. É observado de que maneira os laptops estão sendo utilizados na escola e se a mobilidade presente nos equipamentos do Prouca está potencializando as novas formas de educação no Ensino Fundamental.

\section{PALAVRAS-CHAVE:}

Tecnologias Móveis. Comunicação. Educação. Mobilidade.

\section{ABSTRACT}

This article aims to make reflections on new pedagogical practices that use Information and Communication Technologies (ICT) in a school of Elementary School in the north of Aracaju. We conducted a case study for the research development and analyzes consider the direct relationship between communication and education. It is observed how the laptops are being used in school and if the mobility present in Prouca's equipment is powering new forms of education in elementary school.

\section{KEY WORDS}

Mobile Technologies. Communication. Education. Mobility. 


\section{RESUMEN}

Este artículo tiene como objetivo realizar reflexiones sobre las nuevas prácticas pedagógicas que utilizan Tecnologías de la Información y Comunicación (TIC) en una escuela de educación primaria en la Zona Norte de Aracaju/Se. Se realizó un estudio de caso para el desarrollo de la investigación y los análisis llevan en cuenta la relación directa entre la comunicación y la educación. Se observa cómo las computadoras portátiles se están utilizando en la escuela y si la mo- vilidad presente en los equipamientos del Prouca está potencializando las nuevas formas de educación en la escuela primaria.

\section{PALABRAS CLAVE}

Tecnologías Móviles. Comunicación. Educación. Movilidad.

\section{INTRODUÇÃO}

0 presente estudo tem por finalidade apresentar uma reflexão sobre a inserção das tecnologias móveis no contexto educacional. A análise existente neste conteúdo foi pautada em uma Investigação Qualitativa em Educação, na Escola Municipal de Ensino Fundamental Prof. ${ }^{\text {a }}$ Maria Thetis Nunes, localizada na zona Norte da capital sergipana.

Pretende-se compreender de que maneira os laptops estão sendo utilizados na escola e se a mobilidade presente nos equipamentos do Programa Um Computador por Aluno (Prouca) está potencializando as novas formas de educação no Ensino Fundamental. Além disso, durante a pesquisa, a ideia é conhecer quais os ambientes virtuais são mais utilizados pelos alunos da Escola Municipal de Ensino Fundamental Prof. ${ }^{a}$ Maria Thetis Nunes.

O estudo será todo pautado na relação existente entre Educação e Comunicação. O objetivo geral é compreender a relação existente entre mobilidade e educação a partir da utilização dos Laptops do Prouca na Escola de Ensino Fundamental Prof. a Maria Thetis Nunes. Para isso, pretende-se verificar como os alunos utilizam os aparelhos - se eles trocam informa- ções, se comunicam, ou apenas realizam as atividades escolares, observar a influência da Cibercultura dentro da escola proposta e entender quais foram as alterações no cenário educacional com a inserção das tecnologias móveis.

Para o desenvolvimento desse projeto, a metodologia utilizada será a pesquisa bibliográfica, documental e entrevistas. 0 estudo será pautado na pesquisa Qualitativa em Educação. Como procedimento de estudo, será feita observação direta e indireta; elaborado um roteiro de entrevistas; criadas categorias de análises; e, por último, análise dos dados obtidos a partir dos referenciais teóricos.

A realização da pesquisa contempla também um estudo de caso. Serão feitas entrevistas abertas com 48 alunos, dos $4^{\circ}$ e $5^{\circ}$ anos - a escolha destas turmas é por serem as que mais realizam atividades com o equipamento do Prouca. Já está sendo realizada uma observação participante - visitando e assistindo algumas aulas - e, durante os intervalos, também há uma conversa com os alunos para perceber como eles utilizam o computador não só durante as aulas e atividades passadas pelo professor. 
O objetivo é identificar o perfil do aluno, observar quem é o estudante que utiliza as tecnologias móveis, considerando o seu contexto socioeconômico, o que eles acham do desenho didático das atividades que são realizadas nos computadores. Verificar também 0 modelo de semiologia que surge a partir da adoção dos novos sistemas comunicacionais interativos e do ciberespaço. A pesquisa ainda encontra-se em desenvolvimento, mas já foi possível verificar, por meio da observação e entrevistas com um grupo focal, que os estudantes, além de conhecerem as tecnologias contemporâneas, interagem entre si trocando informações. Este estudo parte do pressuposto que existe uma direta relação entre a informação e o processo de construção do conhecimento. Desta forma, todos os envolvidos no processo de comunicação atuam de uma maneira muito mais participativa.

Quanto ao desenvolvimento da pesquisa, até agora, foram lidos os estudos e textos de autores como Marshall McLuhan, Lúcia Santaella, André Lemos, Eduardo Neiva, Nelson Pretto, Jürgen Habermas, entre outros autores.

A escola onde é realizada a pesquisa está localizada na zona Norte de Aracaju. A instituição é de Ensino Fundamental e durante a manhã as turmas são do $1^{\circ}$ ao $5^{\circ}$ anos - as que mais utilizam as tecnologias móveis - e à tarde as turmas são do $5^{\circ}$ ao $9^{\circ}$ ano. Durante a manhã são 200 alunos, sendo 24 em uma turma do $4^{\circ}$ e 24 na do $5^{\circ}$ ano - as que serão utilizadas para a realização das entrevistas com os estudantes durante a pesquisa. No período da tarde, a escola conta com 204 estudantes.

Os alunos que frequentam a instituição são, na maioria, da classe média baixa e moradores do bairro América. Os pais dos estudantes possuem baixa escolaridade. Nas reuniões da escola, na maioria das vezes são as mães que participam. A conexão de internet da escola não possui uma alta velocidade (chegando apenas a um mega) e os alunos menores, do $1^{\circ}$ ano, não levam o equipamento do Prouca para casa para evitar os casos de assalto - devido serem mais indefe- sos, o índice é maior que nas outras turmas. Na última visita realizada na escola, no dia 27 de setembro, foi constatado que o Prouca estava sem coordenadora, pois a professora responsável pelo programa no Colégio havia solicitado para não mais desempenhar a atividade - um dos motivos que ela alegou é que havia passado em um concurso para ministrar aulas de Biologia em outra escola da rede estadual, por isso ela ficaria apenas um expediente na escola.

A pesquisa na Escola ainda encontra-se em andamento e tem o término previsto para o segundo semestre de 2013. Esta escola, em Aracaju, é uma das beneficiadas pelo Programa Um Computador por Aluno (Prouca). Em 2010, foi implantada, no Brasil, a segunda fase deste programa, criado a partir da Lei $n^{\circ}$ 12.249, de 10 de junho de 2010. 0 Art. $7^{\circ}$ estabelece que o Prouca

\begin{abstract}
[...] tem o objetivo de promover a inclusão digital nas escolas das redes públicas de ensino federal, estadual, distrital, municipal ou nas escolas sem fins lucrativos de atendimento a pessoas com deficiência, mediante a aquisição e a utilização de soluções de informática, constituídas de equipamentos de informática, de programas de computador (software) neles instalados e de suporte e assistência técnica necessária ao seu funcionamento.
\end{abstract}

Vale salientar que a primeira fase do Prouca, denominada de pré-piloto, foi realizada em 2007 em cinco escolas nas seguintes cidades brasileiras: São Paulo-SP, Porto Alegre-RS, Palmas-TO, Piraí-RJ e Brasília-DF. E o principal objetivo deste programa é promover a inclusão digital por meio da distribuição de um computador portátil (laptop) para cada estudante e professor nas escolas públicas de educação básica no Brasil.

0 propósito com a pesquisa é entender o que mudou na educação além da forma instrumental de usar as tecnologias móveis e, para este estudo, realizo uma investigação qualitativa na escola proposta, utilizando para a coleta de informações entrevistas, além da observação. Esta, por sua vez, assemelha-se à apresentada na obra 0 Signo de Três, adotada pelo 
personagem fictício Sherlock Holmes e o filósofo e cientista Charles Peirce. Vale destacar que a análise dos signos contribui de maneira significativa no desenvolvimento do estudo. Como ressalta Eco e Sebeok (1991, p.75-76), ao apresentar a importância da observação durante a pesquisa:

Os eventos empíricos, porém, devem ser interpretados em termos de considerações teóricas estabelecidas. Assim, 'quando um fato parece se opor a uma extensa cadeia de deduções, isso prova, invariavelmente, que é capaz de comportar alguma outra interpretação'. Em um sentido verdadeiramente prático e real, o método de Sherlock antecipou a ênfase contemporânea da Sociologia sobre as relações interativas entre teoria e pesquisa.

Seguindo esta mesma linha de raciocínio, a observação realizada na Escola é pautada em uma investigação que segue os passos estabelecidos para uma pesquisa qualitativa. Dessa forma é necessário realizar um mergulho no universo da pesquisa para entender as suas causas, consequências e o porquê de determinado estudo ter sido desenvolvido. Como afirmam Bogdan e Biklen (1991), a investigação qualitativa é descritiva, ou seja, os dados colhidos deverão ser analisados com toda a sua riqueza. Dessa forma, em cada fase da pesquisa é considerado um estudo de caso diferente, de acordo com o que é percebido na observação.

O plano geral do estudo de caso pode ser representado como um funil. Num estudo qualitativo, o tipo adequado de perguntas nunca é muito específico. 0 início do estudo é representado pela extremidade mais larga do funil: os investigadores procuram locais ou pessoas que possam interessar-lhes, organizam então uma malha larga, tentando avaliar o interesse do terreno ou das fontes de dados para os seus objetivos. (BOGDAN e BIKLEN, 1999, p.89).

Ao estabelecer o contato com os professores e também com os alunos, detectei a importância de analisar os indícios de como se deve proceder na coleta das informações no momento da pesquisa, buscou-se entender e compreender o objeto de estudo e também o método aplicado, assim como um detetive. “À medida que vai conhecendo melhor o tema em estudo, os planos são modificados e as estratégias seleccionadas" (BOGDAN; BIKLEN, 1999, p. 90). Dessa forma, existem diversos tipos de estudos qualitativos e cada um deles necessita de métodos específicos para realizar uma avaliação, a possibilidade de realização e ainda os procedimentos que devem ser adotados.

[...] ao longo das aventuras, Sherlock insiste na grande familiarização que deve ter o investigador com o seu problema, pois familiaridade trará clarificação. Ele nota que "é um equivoco confundir estranhamento com mistério’ (ECO; SEBEOK, 1991, p. 76).

Vale destacar que algumas particularidades são pertinentes à pesquisa científica, mas, de um modo geral, deve-se considerar, além do problema proposto, quais os processos de pensamento e investigação guiam os estudos e também a relação entre as pistas visível e invisível existentes no contexto/realidade estudado. Segundo Minayo (1999), a abordagem qualitativa não pode pretender o alcance da verdade, ou seja, apresentar o que é considerado como certo ou errado. Ao contrário, "ela deve ter como propósito a compreensão da lógica que permeia a prática que se dá na realidade".

Durante o estudo foi utilizada uma observação dos signos existentes e encontrados no local da pesquisa - o material empírico - assim como propõe Charles Pierce, pai da semiótica moderna, considerando que "um Signo faz a mediação entre seu objeto e seu significado" (ECO; SEBEOK, 1991, p. 6). E no campo empírico, que compreende a escola e, consequentemente, os atores sociais lá existentes, os professores e alunos, trabalha-se também com entrevistas que são semiestruturadas e gravadas para posteriormente serem transcritas. Dessa forma, é necessário sempre procurar colher as informações dos entrevistados.

A fala é um meio e um meio fluído, percorrível, andável. A fala não está dada, ela não está morta, não está perenizada na gravação. Ela fica criando-se a si mesma, ecoando seus sons, por vezes inaudíveis e por vezes absolutamente significados. As falas estão em 
estado bruto. Elas se intercomunicam com quem as escutam, com os conceitos... Quanto mais conexões o pesquisador puder estabelecer mais as falas falam... Elas têm potência. (FELDENS, 2008, p.33)

Como salienta Feldens (2008), as falas estão em estado bruto e elas possuem potência, além disso, elas intercomunicam com quem as escuta e "quanto mais conexões o pesquisador puder estabelecer mais as falas falam" (idem, p. 33). Sendo assim, esta pes-

\section{TECNOLOGIAS DA INFORMAÇÃO E COMUNICA- ÇÃO E EDUCAÇÃO}

É claramente perceptível que a sociedade contemporânea sofreu significativas alterações no contexto social, político, econômico e cultural com o uso das Tecnologias da Informação e Comunicação (TIC). Ao observamos o cenário da comunicação e da educação é visível que as mídias e suas linguagens atuam como instrumentos mediadores no que se refere à disseminação do conhecimento. Dessa forma, é extremamente relevante entender e analisar que o processo de comunicação ultrapassa os limites da codificação e decodificação das mensagens, sendo assim, ele encontra-se presente na evolução social, política, econômica e nas mudanças de paradigmas de diversos grupos sociais.

Seguindo esta linha de raciocínio, a análise das Ciências da Comunicação e a sua direta correspondência com a Educação, por meio de uma ótica deontológica, nos leva a detectar que ela adquire um compromisso prioritário no que se refere à compreensão da relação ensino e aprendizagem. Partindo deste pressuposto, é possível perceber o valor da informação na sociedade contemporânea e, além disso, a sua associação com o advento das tecnologias. De acordo com Lévy (1998), em seu livro “As Tecnologias da Inteligência: 0 futuro do pensamento na era quisa pretende ainda colher mais entrevistas e falas tanto dos professores como também dos alunos, para que dessa forma seja possível entender, além do que é perceptível, quais as alterações proporcionadas no cenário educacional, proposto com a inserção das tecnologias móveis, e para isso são utilizados como referencial teórico, conceitos estudados na Educação, como Tecnologias Contemporâneas, Comunicação e Educação e Mobilidade. da informática”, com o desenvolvimento das tecnologias surge novas maneiras de conviver e pensar,

\begin{abstract}
As relações entre os homens, o trabalho e a própria inteligência dependem, na verdade, da metamorfose incessante de dispositivos informacionais de todos os tipos. Escrita, leitura, visão, audição, criação, aprendizagens são capturados por uma informática cada vez mais avançada. Não se pode mais conceber a pesquisa científica sem uma aparelhagem complexa que redistribui as antigas divisões entre experiência e teoria. Emerge, neste final do século XX, um conhecimento por simulação que os epistemologistas ainda não inventaram (LÉVY, 1998, p. 7).
\end{abstract}

Sendo assim, as TIC favorecem a transmissão das mensagens de maneira eletrônica - é oferecido ao homem o acesso ao espaço virtual, conhecido como ciberespaço - com o surgimento das interfaces cria-se uma interligação entre a realidade e a virtualidade. E o propósito com a pesquisa é realizar reflexões acerca das novas práticas educacionais que utilizam as TIC como meio de divulgação da informação - o que se pretende verificar é se as tecnologias móveis potencializam novas formas de educação. E neste cenário existe uma forte relação entre o agir comunicativo - conceito utilizado por Jürgen Habermas e a educação, 
Como tradição cultural, a linguagem entra na ação comunicativa; pois, só as significações intersubjetivamente válidas e constantes, que se obtém da tradição, facultam orientações com reciprocidade, isto é, expectativas complementares de comportamento. Assim, a interação depende das comunicações linguísticas que se tornam familiares (HABERMAS, 1968, p.31).

Dessa forma, é por meio das estruturas simbólicas do mundo da vida ${ }^{4}$ que acontecem os processos de aprendizagem. Estes por sua vez, são pertinentes a práxis educativa. Nesta linha de raciocínio, a educação compreende uma ação social. Estudar as transformações sociais com o advento das TIC leva a compreensão não só do contexto social, como também econômico, político e também cultural do País. Para atender as necessidades e acompanhar as transformações, o Governo apresenta ações e programas com o objetivo de inserir as tecnologias na educação.

Ao observar o cenário da comunicação e da educação é visível que as mídias e suas linguagens atuam como instrumentos mediadores no que se refere à disseminação do conhecimento, é possível visualizar essa realidade, ao perceber que desde a década de 1980 o governo brasileiro vem desenvolvendo ações, programas e projetos com o objetivo de inserir na educação o uso das TIC.

Os avanços tecnológicos, cada vez mais, favorecem a utilização dos programas das redes digitais que reúnem todos os setores da indústria da comunicação, permitindo assim que o surgimento de novas linguagens e no contexto das TIC existe uma convergência entre as mídias no espaço cibernético. Este ciberespaço, por sua vez, segundo Lévy (1998), é o ambiente onde os acontecimentos estão em constantes transformações,

[...] nessa medida o ciberespaço deve ser concebido como um mundo virtual global coerente, independente de como se acede a ele e como se navega nele. Tal qual

4 As estruturas simbólicas do mundo da vida referem-se à tradição cultural, inserção na sociedade e a formação da personalidade. Cf. HABERMAS, Teoria de la acción comunicativa: complementos y estúdios prévios. Madrid: Catedra, 2001, p. 498. uma língua, cuja consistência interna não depende de que os seus falantes estejam, de fato, pronunciando-a, pois, eles podem estar todos dormindo, em um dado momento imaginário, o ciberespaço, como uma virtualidade disponível, independe das configurações específicas que um usuário particular consegue extrair dele. Além disso, há várias maneiras de se entrar no ciberespaço. Pelas animações sensíveis de imagens no monitor do vídeo controlado pelo mouse, passando pela tecnologia da realidade virtual, que visa recriar o sensório humano tão plenamente quanto possível, até os eletrodos neurais diretos. (SANTAELLA, 2004, p. 41)

Partindo desse pressuposto, ao considerar a existência de uma sociedade do conhecimento, é válido salientar que vivemos agora em um movimento, ou seja, voltamos a ser nômades.

O espaço do novo nomadismo não é o território geográ-
fico, nem das instituições dos Estados, mas um espaço
invisível de conhecimentos, saberes, potências de pen-
samento em que brotam e se transformam qualidades
do ser, maneiras de construir sociedade. Não os organo-
gramas do poder, nem as fronteiras das disciplinas, tam-
pouco as estatísticas dos comerciantes, mas o espaço
qualitativo, dinâmico, vivo da humanidade em vias de se
auto-inventar, produzindo seu mundo (LÉVY, 1998, p.15).

Neste contexto, surge um novo modelo da relação entre homem e máquina, "o que passa a predominar não é mais a criação dos objetos, mas a sua substituição por mensagens que circulam, poderosamente, pelas redes sociais" (NEIVA, 1996, p. 94). No ciberespaço qualquer informação podem se tornar habitáveis por conta da sua velocidade de circulação. Existe um afluxo avassalador dos signos. Estes, por sua vez, proporcionam uma significativa dilatação que tende ao infinito das bordas difusas do ciberespaço e para as novas órbitas de circulação das linguagens. Santaella (2007) ressalta que o espaço virtual não surgiu com o propósito de substituir o físico, mas de adicionar funcionalidade no processo de codependência.

Seguindo essa linha de raciocínio, inexoravelmente essas linguagens encontram-se atreladas aos corpos em movimento, e as tecnologias da inteligência 
estão relacionadas às transformações e convergências das mídias cada vez mais avançadas que mesclam a escrita, visão e audição. Para Lévy (1999, p. 17),

\begin{abstract}
[...] vivemos hoje em dia uma destas épocas limítrofes na qual toda a antiga ordem das representações e dos saberes oscila para dar lugar a imaginários, modos de conhecimento e estilos de regulação social, ainda pouco estabilizados. Vivemos um destes raros momentos em que, a partir de uma nova configuração técnica, quer dizer, de uma nova relação com o cosmos, um novo estilo de humanidade inventado.
\end{abstract}

Ao perceber as práticas de interações no ciberespaço, Santaella (2004, p. 11) defende que "o receptor de uma hipermídia ou usuário, como costuma ser chamado, coloca em ação mecanismos, ou melhor, habilidades de leitura muito distintas daquelas que são empregadas pelo leitor de um texto impresso como o livro". Navegando nos hipertextos virtuais decodificamos as mensagens e temos a possibilidade de transitar por diferentes lugares, sendo assim as experiências vividas na internet e por outras mídias têm produzido transmutações nos nossos conceitos de tempo, espaço, e, além disso, também promovendo alterações no modo de viver, aprender, agir, na nossa afetividade, sensualidade, nas crenças que temos e nas emoções que nos assomam (SANTAELLA, 2007).

Sem dúvida, com o desenvolvimento acelerado dos aparatos tecnológicos cada vez menos a comunicação se encontra associada aos lugares fixos. Ainda segundo Santaella (2007, p.25), "nesta era de comunicação móvel, todos testemunhamos o desaparecimento progressivo dos obstáculos materiais que até agora bloqueavam os fluxos dos signos e das trocas de informação".

Sendo assim, estar na rede é permitir passar outras experiências, transitando por diferentes espaços e lugares, possibilitando distintas formas de relações sociais. E o que chamamos a atenção neste artigo é que as tecnologias, em especial as móveis, nos permitem vivenciar uma mobilidade tanto física quanto virtual.

\section{COMUNICAÇÃO E MOBILIDADE}

O significativo desenvolvimento das tecnologias móveis cada vez mais tem permito a população o acesso ao ciberespaço - o que promove uma participação na rede como produtor e autor dos conteúdos - verificamos transformações nos aspectos socioculturais. “A era da pós-informação vai remover as barreiras da geografia. A vida digital exigirá cada vez menos que você esteja num determinado lugar e em determinada hora" (NEGROPONTE, 1999, p. 159).

Assim, com o surgimento de aparelhos celulares com diversas funcionalidades, tablets, smartphones, netbooks entre outros equipamentos torna-se possível detectar além de um processo de inclusão digital, alterações no âmbito cultural, sociocomunicacional e educativo das tecnologias da mobilidade. Os vídeos, mensagens e imagens passam a ser enviados em uma velocidade de tempo ainda maior. Entretanto, de acordo com Lemos (2009, p. 08) "falar de tecnologias móveis, mídias móveis, espaço urbano e mobilidade no Brasil exige uma visão aguçada e atenta aos diversos paradoxos desse país".

$\mathrm{Na}$ atualidade as tecnologias móveis aceleraram ainda mais as trocas de informações, o que nos leva a perceber o surgimento de novos fenômenos comunicacionais. Como demonstra Silva (2009, p. 70) ocorre o aparecimento de "novos processos de produção, 
consumo e circulação da informação no campo do jornalismo em interação com o próprio espaço urbano. Estas mobilidades são interligadas e potencializadas com as tecnologias da comunicação móvel”. Vale destacar que, de acordo com Santaella (2004), existe uma interatividade por conta da união das atividades mentais com as percepctivo-corporais.

Não há separação entre mente e corpo, quando se navega no ciberespaço. Ao contrário, embora o corpo pareça imóvel, enquanto a mente viaja, os sentidos internos do corpo estão em tal nível de atividade, que o corpo que dá suporte às interferências mentais de quem navega é um corpo sensorialmente febril, internamente agitado. (SANTAELLA, 2004, p. 14)

Dessa forma, existem inter-relações do verbal, visual e sonoro na hipermídia, justamente por conta da convergência existente nas tecnologias móveis. Ao detectarmos esta convergência, devemos nos atentar para a existência de uma multiplicidade de linguagens.

Segundo Jekins (2009), ocorre uma transformação midiática que é pautada na correlação entre mídias distintas que foram criadas em momentos diferentes. Sendo assim, elas proporcionam alterações comportamentais no tocante ao seu uso e estas transformações, por sua vez, refletem na postura do público que foi destinada.

\section{EDUCAÇ̃̃O E O USO DAS TECNOLOGIAS MÓVEIS}

Ao analisar o cenário educacional brasileiro, mesmo com todos os avanços no campo tecnológico e científico dentro das escolas, as alterações não aconteceram de maneira tão rápida como nos demais segmentos da sociedade. Vale relembrar que a escola, na atualidade, não é a única responsável pela transmissão das informações e consequentemente do co-
Conectando na tela, por meio de movimentos comandos de um mouse os nexos eletrônicos dessas infovias, o leitor vai unindo, de modo a-sequencial, fragmentos de informações de natureza diversas, criando e experimentando, na sua inter-relação com o seu potencial dialógico da hipermídia, um tipo de comunicação multilinear e labiríntica. (SANTAELLA, 2004, p. 12)

A comunicação e a aprendizagem ocorrem de maneira colaborativa, os atores sociais que utilizam as tecnologias móveis conseguem uma viabilização ao acesso ubíquo no ciberespaço. Dessa forma, as transformações não ocorrem somente no que se refere à transmissão da informação, mas também nas relações sociais.

As revoluções tecnológicas dos últimos dois séculos, voltadas prioritariamente para a produção exacerbada de bens de consumo, tanto materiais quanto simbólicos, tornaram a urdidura dos espaços de existência, nas sociedades industriais e pós-industriais, extremamente intricada e complexa. (SANTAELLA, 2007, p. 173)

Na contemporaneidade, as mudanças nos processos de comunicação ocasionadas pela mobilidade nos leva a repensar qual o papel e os impactos na Educação com a inserção das tecnologias móveis. Além disso, devemos observar como a presença e o uso das TIC no espaço escolar promove alterações nos modos de ensinar, aprender e trocar informações.

nhecimento, por isso, existe uma urgência no que se refere a repensar as práticas pedagógicas.

Neste contexto, vale analisar e considerar o papel das TIC no tocante a realidade educacional. Ou seja, no ambiente escolar e fora dele os estudantes interagem nas redes e compartilham produções, dessa maneira, 
[...] estão gerando uma nova razão que, em princípio, é incompatível com o atual sistema educacional que permanece fechado, linear, baseado em uma razão cartesiana, a qual vem sendo colocada em questão em todos os espaços fora da escola. (PRETTO, 1999, p. 105)

Diversas reflexões são necessárias serem feitas quando se realiza qualquer tipo de investigação, neste caso especifico na linha de Pesquisa Educação e Comunicação, é válido pensar, com a chegada das tecnologias móveis na escola, quais são as transformações no tocante a comunicação e consequentemente no modo de aprender e ensinar? Para esta perspectiva, como afirma Araújo (2007) a grande novidade ocasionada com o uso do computador encontra-se no uso do dispositivo comunicacional, este por sua vez, possibilita a troca de informações entre todas as pessoas que usam a interface.

O papel do aluno, do professor, da avaliação e até da própria definição do que é saber estão sendo repensados, à medida que computadores e redes eletrônicas invadem os espaços de aprendizagem tradicionais, ofertando inovações de imagem, som, movimento, hipertextualidade, virtualidade e realidade virtual. (FILATRO, 2004, p. 29-30)

No cenário educacional o uso destas tecnologias potencializam os espaços intersticiais de aprendizagens e, além disso, também as produções em rede compartilhadas pelos alunos. Conforme salienta Santaella (2007, p. 236),

Nas redes do ciberespaço não só os caminhos são móveis, como também os nós. Enquanto nas conexões ancoradas, os computadores e telefones ocupavam lugares fixos, nas conexões móveis e continuas os telefones representam pontos de conexão móveis, mobilidade que lhes é dada pelo usuário que circula pelos espaços físicos. Duplo nomadismo e dupla mobilidade, portanto.

Como salienta Augé (2010, p.99) “pensar a mobilidade é pensá-la em diversas escalas para tentar compreender as contradições que minam nossa história" dessa forma, ao analisar os traços pertinentes da so- ciedade contemporânea, a partir das experiências do Prouca torna-se necessário compreender a realidade e como a inserção das tecnologias móveis na escola promoveram alterações não só comportamentais, como também no que se refere ao processo de ensino e aprendizado.

\begin{abstract}
Pensar a mobilidade é também aprender a repensar o tempo. A ideologia ocidental, com o tema fim das grandes narrativas e do fim da história, estava em atraso em relação ao evento: ela falava de uma época sem se dar conta de que nós estávamos já grandemente engajados numa nova época. Abordava os novos tempos com palavras antigas e instrumentos ultrapassados. As políticas falam hoje de um mundo multipolar, mas seria preciso reconhecer que os novos polos surgem de experiências históricas originais que não convém abrigar hoje sob rótulo de fim da história (AUGÉ, 2010, p. 100-101).
\end{abstract}

Como a pesquisa ainda encontra-se em andamento, muitos dados ainda serão colhidos, entrevistas feitas e alterações nos procedimentos metodológicos podem ocorrer. Ainda poderão ser realizados estudos comparativos entre a escola da capital sergipana e uma de outra localidade, isso dependerá do desenvolvimento da pesquisa.

É possível verificar a existência de uma direta relação de codependência entre o mundo real e o virtual, as mudanças de paradigmas e como existe uma inter-relação entre as práticas comunicativas e a educação. Um dos desafios é demonstrar que o uso das tecnologias móveis reflete nas interações sociais e neste contexto no cenário educacional, além da sua direta relação com o advento tecnológico. Por meio da mobilidade é possível observar e repensar diferentes formas de relações interpessoais e ainda transformações no âmbito não só comunicacional, mas também na realidade escolar brasileira com a implantação de iniciativas como o Prouca, onde podemos pensar nas suas causas e nas consequências que refletem na adoção de novas práticas pedagógicas. 


\section{REFERÊNCIAS}

AUGÉ, Marc. Por uma antropologia da mobilidade. Maceió. Edufal: Unesp, 2010.

BOGDAN, R. C. e BIKLEN, S. K. Investigação Qualitativa em Educação. Portugal: Porto Editora LTDA, 1999.

ECO, Umberto e SEBEOK, Thomas A. 0 signo de Três. São Paulo: Editora Perspectiva, 1991.

FELDENS, Dinamara G. Cartografias da ditadura e suas moralidades: os seres que aprendemos a ser. Maceió. EDUFAL, 2008.

FILATRO, Andrea. Design Instrucional Contextualizado. Educação e tecnologia. São Paulo: Editora SENAC, 2004.

HABERMAS, Jürgen. Técnica e ciência como ideologia. Trad. Artur Morão, Lisboa: Edições 70, 1968.

HABERMAS, Jürgen.Teoria de la acción comunicativa: complementos y estúdios prévios. Trad. Manuel Jiménez Redondo. Madrid: Catedra, 2001.

JENKINS, Henry. Cultura da Convergência. São Paulo: Aleph, 2009.

LEMOS, André. Arte e mídia locativa no Brasil. In: LEMOS, André; Das tecnologias móveis de comunicação no Brasil. Salvador: EDUFBA, 2009.

LÉVY, Pierre. As tecnologias da inteligência. São Paulo: Editora. 34, 1993.

LÉVY, Pierre. Cibercultura. São Paulo: Editora 34, 1999.
LÉVY, Pierre. A inteligência Coletiva. Por uma antropologia do Ciberespaço. São Paulo: Edições Loyola, 1998.

MINAYO, Maria Cecília de Souza. 0 desafio do conhecimento: pesquisa qualitativa. 6.ed. São Paulo: Hucitec, 1999.

MINISTÉRIO DA EDUCAÇÃO. Lei no 12.249 , de 10 de junho de 2010. Disponível em http://www.uca.gov.br/ institucional/index. jsp. Acesso em: 05 maio 2011.

NEGROPONTE, Nicholas. A Vida Digital. Rio de Janeiro: Companhia das Letras, 1995.

NEIVA. Eduardo. 0 que aprender com as Antigas Catástrofes: comunicação, técnica e sociedade. São Paulo: Editora Ática, 1996.

PRETTO, Nelson De Luca. 0 futuro da escola. Entrevista para emprego e educação para o trabalho. 28/11/1999. Disponível em: <http://www2.ufba. $\mathrm{br} / \sim$ pretto/textos/jb281199.htm $>$. Acesso em $08 \mathrm{de}$ maio de 2012.

SANTAELLA, Lucia. Cultura das mídias. São Paulo: Experimento, 1996.

SANTAELLA, Lucia. Navegar no ciberespaço: o perfil cognitivo do leitor imersivo. São Paulo: Paulus, 2004.

\section{SANTAELLA, Lucia. Linguagens líquidas na era da} Mobilidade. SP: Paulus, 2007.

SILVA, Fernando Firmino da. Tecnologias móveis como plataformas de produção no jornalismo. In: LEMOS, André; das tecnologias móveis de comunicação no Brasil. Salvador: EDUFBA, 2009. 
I Graduada em Comunicação Social Bacharelado em Jornalismo - Universidade Tiradentes Mestranda em Educação - Unit. Componente do Grupo de Pesquisa Educação, Tecnologias da Informação e Cibercultura (GETIC/ Avaliado em: 20 dez. 2012 Aceito em: $21 \mathrm{dez} .2012$

CNPq). Atualmente é bolsista profissional atuando como jornalista no Programa de Comunicação e Difusão Científica na Fundação de Apoio à Pesquisa e à Inovação Tecnológica do Estado de Sergipe (Fapitec/SE). E-mail: livialessa_13@hotmail.com 